\title{
Relaxation behaviors of Vickers indentations in soda-lime glass
}

\author{
Hiroshi SAWASATO, Satoshi YOSHIDA, ${ }^{\dagger}$ Toru SUGAWARA, Yoshinari MIURA and Jun MATSUOKA
}

Center for Glass Science and Technology, The University of Shiga Prefecture, 2500, Hassaka, Hikone, 522-8533 Shiga

\begin{abstract}
Permanent deformation of glass under a sharp diamond indenter can be divided into two modes; plastic (or shear) flow and densification. The former is a volume-conservative deformation process, and the latter includes volume contraction. It is very important to recognize how much these two processes contribute to the formation of indentation impression in order to understand permanent deformation of glass. In this study, using an atomic force microscope (AFM), annealing recovery of indentation impression in soda-lime glass was studied under several annealing conditions. After annealing, large shrinkage of Vickers indentation was observed and it was attributed to relaxation of densified volume under the indenter. The recovery ratio of indentation volume by annealing increased up to $71 \%$ with increasing the annealing temperature to the glass transition temperature $\left(539^{\circ} \mathrm{C}\right)$. Relaxation of densified volume was observed even at a low annealing temperature $\left(214^{\circ} \mathrm{C}\right)$. It is suggested that the recovered region by annealing at a given temperature is determined from the microscopic glass density which is affected by the pressure distribution under the Vickers indenter.
\end{abstract}

(02008 The Ceramic Society of Japan. All rights reserved.

Key-words : Soda-lime glass, Indentation, Vickers hardness, AFM, Densification, Relaxation

[Received March 27, 2008; Accepted June 19, 2008]

\section{Introduction}

Indentation test is one of the simple and useful techniques for evaluating mechanical property of various kinds of materials, including brittle ceramics. Hardness of a material is usually determined from the diagonal length of indentation impression after unloading by using an optical microscope. On the other hand, Oliver and Pharr proposed an evaluation technique of hardness and Young's modulus using a depth sensing indenter, or nanoindenter. ${ }^{1)}$ The Oliver-Pharr method enables one to determine mechanical properties of various types of elastoplastic materials even in microscopic regions without measuring the diagonal length of indentation. As a conventional hardness test, Vickers indentation test is one of the most wide spread indentation tests. It consists of indenting the material with a diamond indenter which has the shape of a squared pyramid with an angle of $136^{\circ}$ between faces. Vickers hardness is the ratio of indentation load to the indentation surface area which is estimated from the diagonal length of indentation impression. Although hardness obtained from the nano-indentation test or from the conventional indentation test is considered as a measure of the resistance of material to permanent deformation, there are very few quantitative studies on the mechanism of irreversible deformation of glass under a sharp diamond indenter. Peter ${ }^{2)}$ suggested that deformation mechanism of oxide glass can be divided into two modes; plastic (or shear) flow and densification. The former is a volumeconservative deformation process, and the latter includes volume contraction. It is very important to recognize how much these two processes contribute to the formation of indentation impression in order to understand permanent deformation of glass.

For example, the formation mechanism of indentation impression in glass affects fracture toughness of glass using an indentation technique. When the Vickers indentation test is performed on a flat glass surface, cracks develop from the corners of indentation impression at a higher indentation load. By measuring the crack

$\bar{\dagger}$ Corresponding author: S. Yoshida; E-mail: yoshida@mat.usp.ac.jp lengths, it is possible to estimate the fracture toughness $\left(K_{\mathrm{c}}\right)$ of brittle ceramics or glasses. This method is the so-called indentation fracture (IF) method expressed as the following equation, ${ }^{3)}$

$$
K_{\mathrm{c}}=0.016 \frac{P}{C^{3 / 2}}\left(\frac{E}{H}\right)^{1 / 2}
$$

where $P$ is the indentation load, $C$, the radius of half penny crack from the center of the indentation, $E$, Young's modulus and $H$, the hardness. The driving force for crack propagation is the residual stress around the indentation. ${ }^{4)}$ The residual stress depends on the deformation mechanism under the indenter. The densification means volume contraction under the indenter, and it does not contribute to the volume strain, which is the origin of the residual stress. It is considered that the larger contribution of densification results in the smaller residual stress around the indentation. ${ }^{5)}$ Therefore, the indentation-induced densification leads to an overestimation of indentation fracture toughness.

The densified volume under the indenter can be almost completely recovered by thermal annealing at a temperature nearby the glass transition temperature $\left(T_{\mathrm{g}}\right)$. This phenomenon is linked with the relaxation behavior of silicate glass densified under a hydrostatic pressure. ${ }^{6,7)}$ Mackenzie showed that the molar volume of densified silica glass approached to that of uncompressed glass by annealing at the temperature ranges from $200^{\circ} \mathrm{C}$ to $1000^{\circ} \mathrm{C}$ for various periods. ${ }^{6}$ Annealing also causes the recovery of indentation impressions. ${ }^{8,9)}$ Using this annealing technique, it was reported that the ratio of densified volume to total indentation volume can be estimated. ${ }^{10)}$ Yoshida et al. measured the indentation volume for various glasses using an atomic force microscope (AFM) before and after annealing, and reported that densification contributions were estimated to be $61 \%$ for soda-lime float glass, $92 \%$ for silica glass and only $4.6 \%$ for bulk metallic glass. ${ }^{10}$ ) Although it is important to know the compositional variation of densification contribution for various glasses, there have been no quantitative analyses taking into consideration of relationship between annealing conditions and recovery of indentation volume. In this study, annealing recovery of indentation impression in 
soda-lime glass is investigated under several annealing conditions. The changes in indentation geometries by annealing are evaluated using an AFM before and after annealing. The effect of annealing conditions on the relaxation of densified volume under the indenter is discussed.

\section{Experimental procedure}

The sample employed was a commercial soda-lime glass with a thickness of $1.3 \mathrm{~mm}$ (Matsunami S-0050, Japan). $T_{\mathrm{g}}$ of the glass is $539^{\circ} \mathrm{C}$ which is shown in the catalogue. The specimen was cut into $10 \mathrm{~mm} \times 10 \mathrm{~mm}$ in size using a diamond glass cutter. Vickers indentations were performed in air $\left(25^{\circ} \mathrm{C}\right.$, r.h. $30 \%$ ) using a dynamic hardness tester (Shimadzu DUH-201, Japan). The maximum indentation load and the loading-unloading rate were $0.3 \mathrm{~N}$ and $0.07 \mathrm{~N} / \mathrm{sec}$, respectively. The indentation dwell time at the maximum load was kept to be $15 \mathrm{~s}$.

After the Vickers indentation test, indentation impressions were observed by using an AFM (Veeco, Nanoscope E, U.S.). After the careful calibration using a standard reference, AFM observations were performed with the contact mode. The scan size and the scan rate were fixed to be $14 \mu \mathrm{m}$ and $1 \mathrm{~Hz}$, respectively. The pixel resolution of captured image was $27 \mathrm{~nm} /$ pixel $(512 \times 512$ pixels in a scan area). The AFM cantilever was a silicon nitride $\left(\mathrm{Si}_{3} \mathrm{~N}_{4}\right)$ tip with a curvature radius of 5 to $40 \mathrm{~nm}$.

The indentation volume and geometries were measured before and after annealing through the procedure illustrated in Fig. 1. The indentation geometries measured are the diagonal length, $L_{\mathrm{c}}$, the opposite-side (face-to-face) length, $L_{\mathrm{s}}$, and the indentation depth, $D$. All the parameters obtained before annealing have the additional subscript "i". After annealing, on the other hand, the

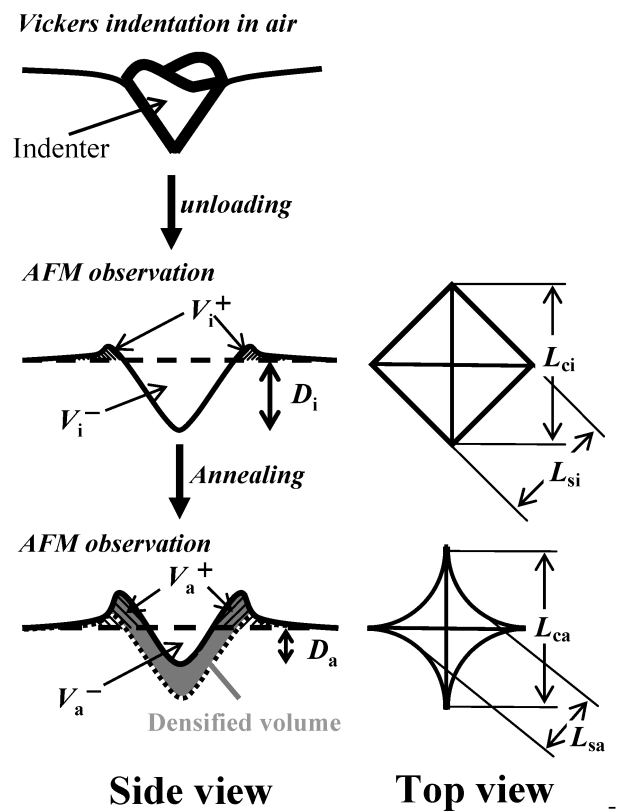

Fig. 1. Schematic illustration of the indentation geometries and volume. parameters with the additional subscript "a" were determined. For example, $L_{\mathrm{ci}}$ denotes the diagonal length before annealing. The volume measurement was also performed before and after annealing. $V^{+}$means the pile-up volume, $V^{-}$means the indentation volume. The indentation volume and pile-up volume were defined as the volumes below and above the flat surface, respectively. After capturing the AFM image, flattening modification included in the AFM software was carried out for eliminating bow and slope of the surface. The indentation geometries and volume were determined using the image analysis function included in the AFM software.

For every indented sample, annealing was performed in air using an electric furnace. A thermocouple in contact with a specimen was used to determine the annealing temperature. The annealing was performed at $T_{\mathrm{g}}\left(539^{\circ} \mathrm{C}\right), T_{\mathrm{g}} \times 0.9 \mathrm{~K}\left(458^{\circ} \mathrm{C}\right), T_{\mathrm{g}}$ $\times 0.7 \mathrm{~K}\left(295^{\circ} \mathrm{C}\right)$ and $T_{\mathrm{g}} \times 0.6 \mathrm{~K}\left(214^{\circ} \mathrm{C}\right)$. The annealing time was changed from $15 \mathrm{~min}$ to $120 \mathrm{~min}$. It took less than $2 \mathrm{~min}$ for the sample to reach a given temperature after the sample was put into the furnace.

After AFM observations before and after annealing, the recovery ratios of indentation length and depth were derived from the following equation,

$$
X_{\mathrm{R}}=\frac{X_{\mathrm{i}}-X_{\mathrm{a}}}{X_{\mathrm{i}}}
$$

where the parameter $X$ is the diagonal length, $L_{\mathrm{c}}$, or the oppositeside length, $L_{\mathrm{s}}$, or the depth, $D$. On the other hand, the volume ratio of annealing recovery, $V_{\mathrm{R}}$, as the recovery ratio calculated by the following equation.

$$
V_{\mathrm{R}}=\frac{\left(V_{\mathrm{i}}^{-}-V_{\mathrm{a}}^{-}\right)+\left(V_{\mathrm{a}}^{+}-V_{\mathrm{i}}^{+}\right)}{V^{-}}
$$

The pile-up volume always increased after annealing $\left(V_{\mathrm{a}}^{+}>V_{\mathrm{i}}^{+}\right)$. It was assumed that the increase in pile-up volume, $V^{+}$, was induced by the recovery of densified volume under the Vickers indenter (see Fig. 1). Therefore, the sum of the changes in the pile-up volume, $\left(V_{\mathrm{a}}^{+}-V_{\mathrm{i}}^{+}\right)$, and in the indentation volumes, $\left(V_{\mathrm{i}}^{-}\right.$ $-V_{\mathrm{a}}^{-}$), was considered as the densified volume.

\section{Results}

In Table 1, indentation geometries and volume before annealing and Vickers hardness which is calculated from the diagonal length of indentation impression are represented. Parameters listed in this Table are the same ones as those shown in Fig. 1, and the experimental uncertainty means the average of standard deviations. Table 2 shows the indentation geometries and volumes after various annealing conditions. All the indentation geometries and volumes are averaged over measurements on 15 indentations for given experimental conditions, and the experimental uncertainty means the average of standard deviations. Annealing was performed for one specimen with 15 indentations under each condition. From Tables 1 and 2, it is turned out that the amounts of shrinkage of opposite-side length and depth of indentation increase with increasing annealing temperature. However, we cannot find any time-dependent change in inden-

Table 1. Indentation Geometries, Volume, and Vickers Hardness of Glass before Annealing. Indentation Load is $0.3 \mathrm{~N}$

\begin{tabular}{lcccccc}
\hline & $L_{\mathrm{ci}} / \mu \mathrm{m}$ & $L_{\mathrm{si}} / \mu \mathrm{m}$ & $D_{\mathrm{i}} / \mu \mathrm{m}$ & $V_{\mathrm{i}}^{+} / \mu \mathrm{m}^{3}$ & $V_{\mathrm{i}}^{-} / \mu \mathrm{m}^{3}$ & $H_{\mathrm{V}} / \mathrm{GPa}^{2}$ \\
\hline Before annealing & 9.78 & 5.90 & 0.78 & 0.27 & 8.20 & 5.82 \\
Experimental uncertainty & \pm 0.07 & \pm 0.08 & \pm 0.02 & \pm 0.07 & \pm 0.18 & \pm 0.04 \\
\hline
\end{tabular}


Table 2. Indentation Geometries and Volume of Glass after Annealing. Indentation Load is $0.3 \mathrm{~N}$

\begin{tabular}{|c|c|c|c|c|c|c|}
\hline \multicolumn{2}{|c|}{ Annealing condition } & \multirow{2}{*}{$\begin{array}{c}L_{\mathrm{ca}} / \mu \mathrm{m} \\
9.71\end{array}$} & \multirow{2}{*}{$\frac{L_{\mathrm{sa}} / \mu \mathrm{m}}{5.61}$} & \multirow{2}{*}{$\begin{array}{c}D_{\mathrm{a}} / \mu \mathrm{m} \\
0.65\end{array}$} & \multirow{2}{*}{$\frac{V_{\mathrm{a}}^{+} / \mu \mathrm{m}^{3}}{0.25}$} & \multirow{2}{*}{$\frac{V_{\mathrm{a}}^{-} / \mu \mathrm{m}^{3}}{6.11}$} \\
\hline & $15 \mathrm{~min}$ & & & & & \\
\hline \multirow[t]{3}{*}{$214^{\circ} \mathrm{C}$} & $30 \mathrm{~min}$ & 9.81 & 5.65 & 0.67 & 0.20 & 6.22 \\
\hline & $120 \mathrm{~min}$ & 9.66 & 5.47 & 0.68 & 0.42 & 5.98 \\
\hline & $15 \mathrm{~min}$ & 9.70 & 5.46 & 0.61 & 0.26 & 5.41 \\
\hline \multirow[t]{3}{*}{$295^{\circ} \mathrm{C}$} & $30 \mathrm{~min}$ & 9.76 & 5.28 & 0.61 & 0.31 & 5.10 \\
\hline & $120 \mathrm{~min}$ & 9.62 & 5.30 & 0.65 & 0.32 & 5.26 \\
\hline & $15 \mathrm{~min}$ & 9.69 & 4.59 & 0.54 & 0.38 & 3.73 \\
\hline \multirow[t]{3}{*}{$458^{\circ} \mathrm{C}$} & $30 \mathrm{~min}$ & 9.50 & 4.31 & 0.50 & 0.54 & 2.99 \\
\hline & $120 \mathrm{~min}$ & 9.76 & 4.43 & 0.50 & 0.32 & 3.20 \\
\hline & $15 \mathrm{~min}$ & 9.64 & 4.09 & 0.47 & 0.68 & 2.74 \\
\hline \multirow[t]{2}{*}{$539^{\circ} \mathrm{C}$} & $30 \mathrm{~min}$ & 9.59 & 4.14 & 0.47 & 0.62 & 2.75 \\
\hline & $120 \mathrm{~min}$ & 9.70 & 4.09 & 0.48 & 0.75 & 2.82 \\
\hline \multicolumn{2}{|c|}{ Experimental uncertainty } & \pm 0.08 & \pm 0.06 & \pm 0.01 & \pm 0.08 & \pm 0.11 \\
\hline
\end{tabular}

tation geometries and volume after more than 15 min annealing at any temperature.

In Fig. 2, the shrinkage of indentation by annealing can be

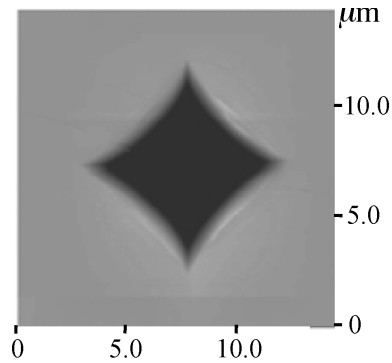

Before annealing

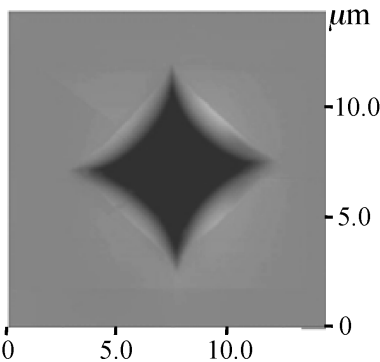

Annealing at $295^{\circ} \mathrm{C}$

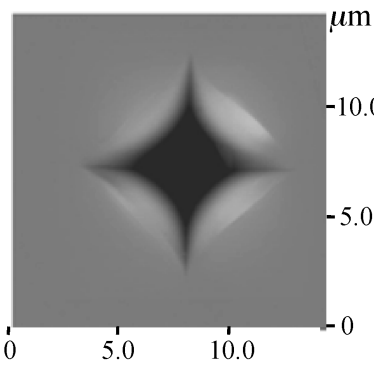

Annealing at $539^{\circ} \mathrm{C}\left(T_{\mathrm{g}}\right)$

2. Variation of top view of ir ture. Annealing time is $120 \mathrm{~min}$.

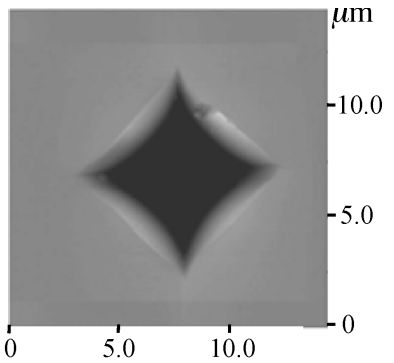

Annealing at $214^{\circ} \mathrm{C}$

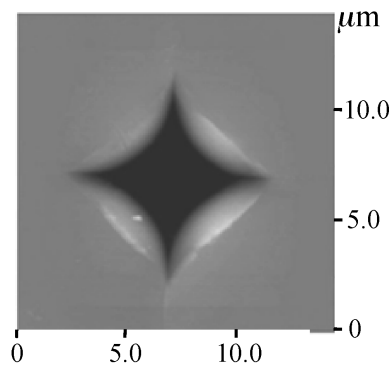

Annealing at $458^{\circ} \mathrm{C}$

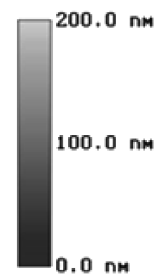

confirmed. Figure 2 shows AFM top views of indentation before and after annealing. In this figure, it is found that the recovery of diagonal length of indentation, $L_{\mathrm{c}}$, is very limited at any annealing temperature. On the other hand, there is a remarkable recovery of opposite-side length, $L_{\mathrm{s}}$, especially by annealing at $458^{\circ} \mathrm{C}$ and $539^{\circ} \mathrm{C}$. In general, cracks developing from the corners of indentation affect the residual stress around indentation impression. Although we can not find any crack in Fig. 2, faint radial cracks with depth of $10 \mathrm{~nm}$ were observed in AFM deflection images for several indentations. However, it was confirmed that there was no difference in geometry and in volume between the indentations with the faint cracks and those without cracks.

Figure 3 shows AFM cross-section profiles of indentation impression before and after annealing. The cross-section planes include the center of indentation, and they are parallel to the diagonal direction or the face-to-face direction. These profiles clearly show that significant recoveries of indentation depth (center of indentation) and of opposite-side (face-to-face) distance by annealing. In addition, it is confirmed that there is no significant change in the diagonal length by annealing at any temperature.

Figure 4 shows the recovery ratios of indentation geometries, which are $L_{\mathrm{cR}}, L_{\mathrm{sR}}$ and $D_{\mathrm{R}}$, and the recovery ratio of volume, $V_{\mathrm{R}}$, as a function of annealing temperature. Annealing time is 120 min. The values of $V_{\mathrm{R}}, D_{\mathrm{R}}$ and $L_{\mathrm{sR}}$, increase with increasing annealing temperature. On the other hand, the recovery ratio of indentation diagonal, $L_{\mathrm{cR}}$, is very limited at any annealing temperature as stated above. The recovery ratio of indentation volume reaches up to $71 \%$ with increasing annealing temperature to $T_{\mathrm{g}}\left(539^{\circ} \mathrm{C}\right)$. It is note worthy that the recovery of indentation volume is found to be $27 \%$ even at low annealing temperature $\left(214^{\circ} \mathrm{C}\right)$. The recovery ratio of indentation geometry increases in the order of $D_{\mathrm{R}}>L_{\mathrm{sR}}>L_{\mathrm{cR}}$ at any annealing temperature.

As for the annealing time dependence of the recovery of indentation, the relationship between the recovery of indentation volume, $\left(V_{\mathrm{i}}^{-}-V_{\mathrm{a}}^{-}\right)+\left(V_{\mathrm{a}}^{+}-V_{\mathrm{i}}^{+}\right)$, and annealing time is shown in Fig. 5. In Fig. 5, very rapid initial recovery of indentation volume is observed within $15 \mathrm{~min}$ at any annealing temperature. After that, the amount of recovered volume is almost constant, and depends only on annealing temperature. 

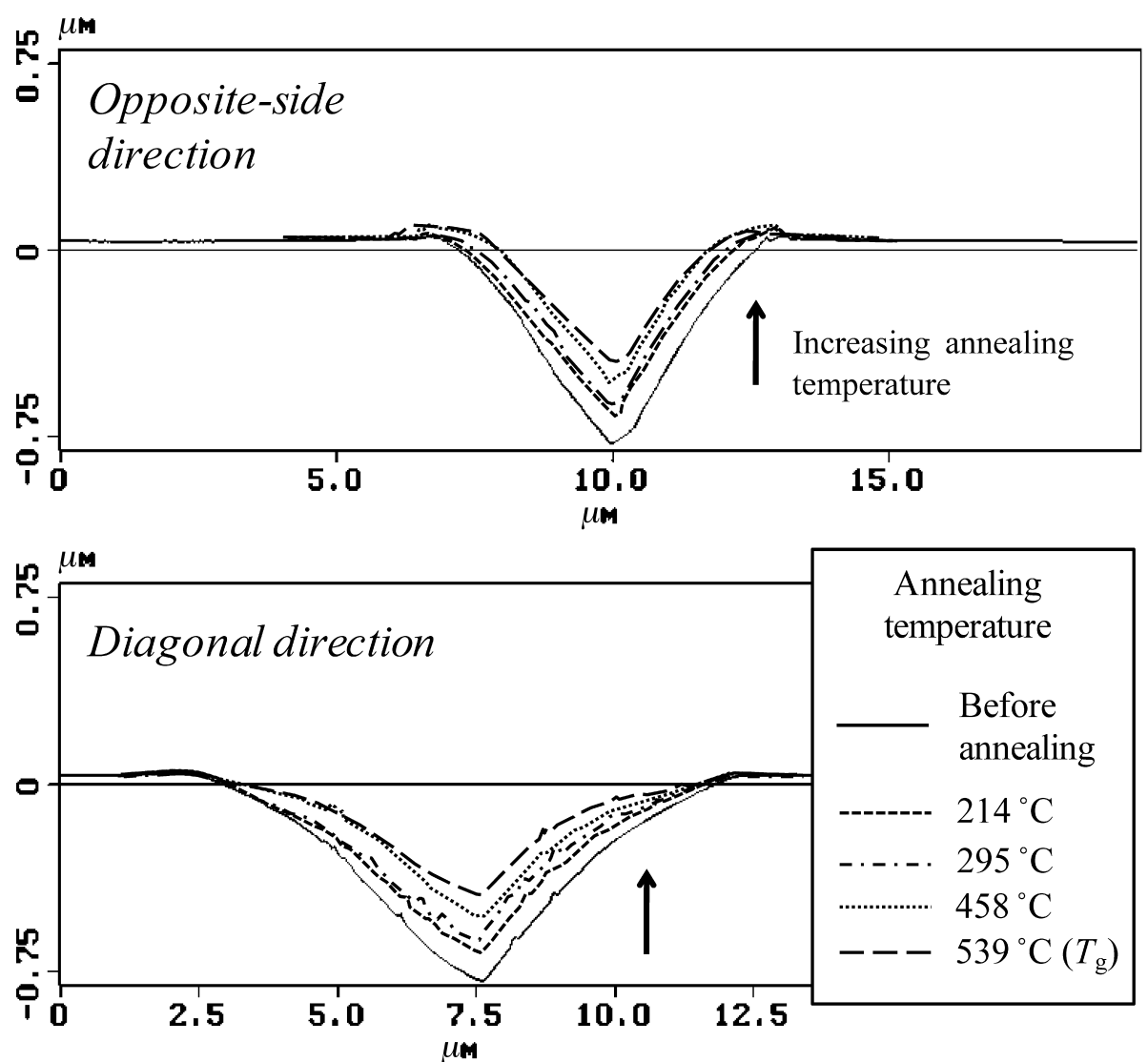

Fig. 3. AFM cross-section profiles of indentation before and after annealing.

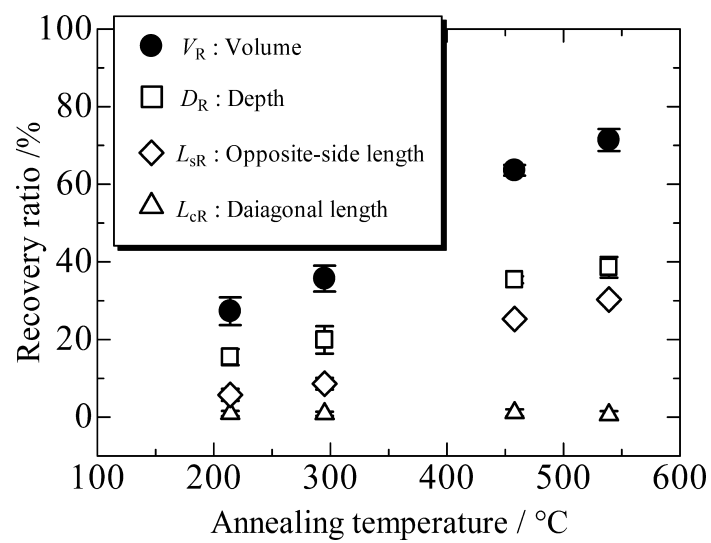

Fig. 4. Variation of recovery ratios with annealing temperature. Annealing time is $120 \mathrm{~min}$

\section{Discussion}

Our results clearly show that soda-lime glass is subjected to densification under the Vickers indenter. The $V_{\mathrm{R}}$ value of $64 \%$ obtained by annealing at $T_{\mathrm{g}} \times 0.9$ is in good agreement with the reported value of $61 \%$ in the previous study. ${ }^{10)}$ Further increase in annealing temperature up to $T_{\mathrm{g}}$ raises the densification contribution to be $71 \%$. At a higher annealing temperature, we must take care that viscous flow affects the shape of indentation impression during annealing. However, there is no evidence that a roundness of the corner or edge of the impression by annealing (Figs. 2 and 3). Therefore, it is considered that viscous flow does

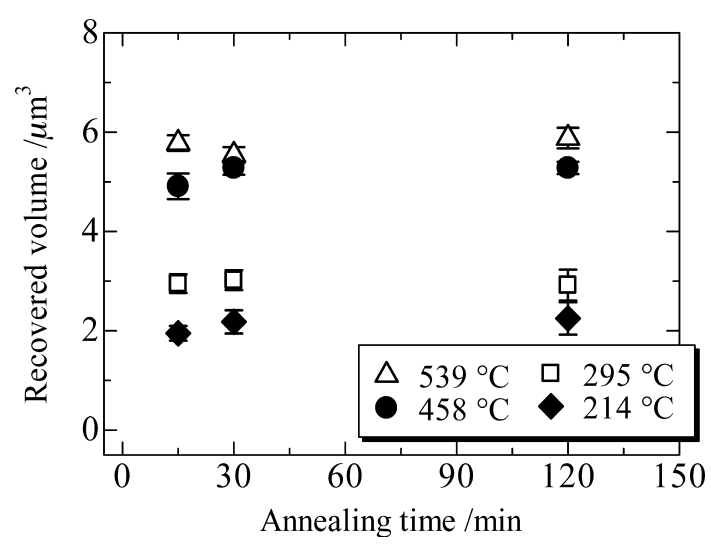

Fig. 5. Variation of recovered volume with annealing time.

not affect the shape of indentation impression under our experimental conditions. This supports that the recovered volume by annealing at $T_{\mathrm{g}}$ is almost comparable with the total densified volume under the indenter. Annealing at a temperature higher than $T_{\mathrm{g}}$ would cause viscous flow mentioned above. In order to confirm this assumption, we will need some experimental data on the viscous flow around the indentation during annealing. Another problem is the relaxation of residual stress, which originates from the elastic/plastic mismatch around the indentation. The relaxation of residual stress means the recovery of plastic deformation, and results in an overestimation of densified volume under the indenter. Kese et al. reported that complete stress relaxation may not be achieved around the indentation in soda- 
lime glass even at $T_{\mathrm{g}} \times 0.97$ for $24 \mathrm{~h} .{ }^{11)}$ However, Agarwal and Tomozawa reported that the silica glass surface which was not an indented surface can be easily relaxed by annealing at around $T_{\mathrm{g}}$ especially in the presence of water. ${ }^{12)}$ More quantitative study will be needed for discussion on the effect of relaxation of residual stress on evaluation of densification under the indentation.

In Fig. 4, it is found that there is almost no shrinkage in the diagonal length of the Vickers indentation. It is suggested that plastic flow is a predominant deformation mechanism at the edge of indentation due to high shear stress or high stress concentration. On the other hand, the large shrinkage by annealing at a higher annealing temperature is observed at the face and the bottom of indentation. This result suggests that densification mechanism gives a major contribution to the indentation deformation both at the face and at the bottom of indentation. This is because the stress under the face of indenter is compressive rather than shear under the edge or because the stress concentration under the face of indenter is not higher than that under the edge.

In Fig. 5, there's no annealing time dependence of the recovered volume. This is quite different from the usual relaxation behavior where the measured value approaches to an apparent equilibrium value at a given rate which is lower at lower annealing temperature and higher at higher annealing temperature. ${ }^{12)}$ The reason of this unusual relaxation behavior is not clear at the present stage, but it would originate from a difference between the stress-induced structure and the temperature-induced structure. From a close look at Fig. 4, it is found that the recovered region by annealing is dependent on annealing temperature. Annealing at $214^{\circ} \mathrm{C}$ prefers the recovery of depth, whereas annealing at the temperatures higher than $458^{\circ} \mathrm{C}$ results in the remarkable shrinkage of face-to-face distance. This probably results from the variety of microscopic density of glass under the indentation impression. Perriot et al. reported the densification mapping under the indentation using microprobe Raman spectroscopy. ${ }^{13)}$ They reported that the bottom of indentation impression is the highest density region $(16 \%)$, and that the density of the region near the sample surface is not so high $(<10 \%)$. The highly densified region with high stressed bonds can be relaxed at a relatively low annealing temperature, because this highstressed state would be thermally unstable. Meanwhile, the less densified region needs high temperature annealing in order to relax the structure into the unstressed one. This would be a reason that the recovered region depends on the annealing temperature.

\section{Conclusion}

The indentation-induced densification in glass was estimated from the volume recovery of indentation by thermal annealing. The recovered volume increases with increasing annealing temperature. The ratio of volume recovery is $27 \%$ for annealing at $214^{\circ} \mathrm{C}$ and $71 \%$ for annealing at $T_{\mathrm{g}}$. The recovery of diagonal length of indentation is very limited at any annealing temperature. The depth recovery starts at a lower annealing temperature, and the recovery of face-to-face distance occurs at higher annealing temperatures. It is considered that the annealing temperature dependence of recovered region comes from the distribution of density of glass under the indentation impression.

\section{References}

1) W. C. Oliver and G. M. Pharr, J. Mater. Res., 7, 1564-1583 (1992).

2) K. W. Peter, J. Non-Cryst. Solids., 5, 103-115 (1970).

3) G. R. Anstis, P. Chantikul, B. R. Lawn and D. B. Marshall, J. Am. Ceram. Soc., 64, 533-538 (1981).

4) B. R. Lawn, A. G. Evans and D. B. Marshall, J. Am. Ceram. Soc., 63, 574-581 (1980).

5) S. Yoshida, J.-C. Sangleboeuf and T. Rouxel, Int. J. Mater. Res., 98, 360-364 (2007).

6) J. D. Mackenzie, J. Am. Ceram. Soc., 46, 470-476 (1963).

7) M. Tashiro, S. Sakka and T. Yamamoto, J. Ceram. Soc. Japan., 6, 108-113 (1964) [in Japanese].

8) J. E. Neely and J. D. Mackenzie, J. Mater. Sci., 3, 603-609 (1968).

9) S. Yoshida, S. Isono, J. Matsuoka and N. Soga, J. Am. Ceram. Soc., 84, 2141-2143 (2001).

10) S. Yoshida, J.-C. Sangleboeuf and T. Rouxel, J. Mater. Res., 20, 3404-3412 (2005).

11) K. Kese, M. Tehler and B. Bergman, J. Eur. Ceram. Soc., 26, 1003-1011 (2006).

12) A. Agarwal and M. Tomozawa, J. Non-Cryst. Solids, 209, 264-272 (1997).

13) A. Perriot, V. Martinez, Ch. martinet, B. Champagnon, D. Vandembroucq and E. Barthel, J. Am. Ceram. Soc., 89, 596601 (2005). 